\title{
Hyperlactatemia and Lactic Acidosis Results in Longer Stay in Intensive Care Units (ICUs) and Development of Co-morbid in Post-operative Cardiac Surgery Patients
}

\author{
${ }^{* 1}$ Junaid Mahmood Alam, ${ }^{1}$ Aijaz Ahmed, ${ }^{1}$ Ishrat Sultana, ${ }^{2}$ Syed Riaz Mahmood \\ ${ }^{1}$ Department of Biochemistry Lab services and Chemical Pathology, Liaquat National Hospital and Medical \\ College, Karachi-74800 \\ ${ }^{2}$ Department of Pathology, Govt Lyari General Hospital, Karachi Pakistan
}

Abstract: Pathology of Hyperlactatemia and lactic acidosis is convoluted, including tissue hypoxia, pulmonary abnormalities, Ischemic shock, hypohemoglobinemia and generalized an-aerobic conditions. All or any one of these conditions may have occurred due to surgical intervention, long-term cardiogeneic syndromes or after long Intensive care stay. Present study described the assessment and correlation of post-operative Hyperlactatemia in cardiac surgery patients to the longer length of stay in Intensive care units (ICUs). Pre-operative and Post operative blood samples were analyzed in seventy five $($ Males $=59$, females $=16)$ cardiac surgery patients for Lactate and other biochemical parameters were according to the prescribed methods. Post-operative blood sample analyses were also performed 4-6 hrs after surgery and after $24 \mathrm{hrs}$ post-operatively. Six hours postoperative assessment of lactate, showed alerted levels, manifesting post-operative complications and development of co-morbid. It was also noted that patients $(n=21)$ with higher lactate $>20 \mathrm{mg} / \mathrm{dl}$ had to stay longer in ICUs (12-18 days stay, average $16.15 \pm 2.50$ days) as compared to those $(n=54)$ with normal range of lactate level (5-9 days stay, average $7.20 \pm 2.10$ days). It is thus concluded that post-operative Hyperlactatemia and lactic acidosis in cardiac surgery patients is a significant condition to detect poor outcome. Additionally post-operative lactate level can predict length of stay in ICUs and any prospect of developing adverse outcome and co-morbid.

Keywords: Hyperlactatemia, lactic acidosis, Intensive care units (ICUs)

\section{Introduction}

Lactic acidosis or Hyperlactatemia are distinguished and potential conditions of inadequate oxygen perfusion in patients of cardiac and critical care surgeries [1]. It was also documented that elevated production of lactate doesn't always meant hypoxic conditions; thus even under non-hypoxic condition, lactate overproduction can also induce co-morbid and adverse outcome [2]. Pathology of Hyperlactatemia and lactic acidosis is intricate, such as tissue hypoxia, pulmonary abnormalities, Ischemic shock, low levels of hemoglobin and generalized an-aerobic conditions that may have occurred due to surgical intervention or long-term cardiogeneic syndromes [3-7]. As a routine, human body continues to receive oxygen through an- aerobic glycolytic pathway even in hypoxic condition, which in-turn induces the overproduction of lactate [8].

Lactate or lactic acid which is also known an acute critical care marker, is mostly analyzed to assess better or worsening outcome in patients undergoing cardiac surgeries [3,9-11]. Moreover, patients with Hyperlactatemia or those with slow normalizing lactate levels reported mortality and $100 \%$ post-operative complication [12]. Furthermore, cessation or slow normalization of elevated lactate levels known to be associated with longer Intensive Care Units (ICUs) stay, frequently in critical care or cardiac surgery patients [9-11].

Present study described the assessment and correlation of post-operative Hyperlactatemia in 
cardiac surgery patients to the longer length of stay in Intensive care units (ICUs).

\section{Materials and Methods:}

\subsection{Patient's selection and Research Protocols:}

This observational retrospective study was conducted at Departments of Biochemistry Laboratory services and Chemical Pathology, Liaquat National Hospital, Karachi and Department of Pathology, Govt Lyari General Hospital, Karachi, for the period Jan 2011 to Jan 2016. Demographic data of all patients undergone cardiac surgeries and admitted to ICUs were collected and documented through review of patients' files. Inclusion criteria is dependent on history of cardiac surgeries over the age $>30$ yrs and $<65$ years. Patients with indigenous multiple surgeries other than cardiac, <30 yrs and >65 yrs, missing history of co-morbid and patients on dialysis were excluded from the study. Data of a total of 156 patients were reviewed, out of which only seventy five ( $\mathrm{n}=75$, males $=59$ and females =16)) were documented as per availability of all analytical data, and pre and post-operative information.

\subsection{Analytical methods and lactate estimation:}

Pre-operative and Post operative blood samples were analyzed for lactate and other biochemical parameters such as uric acid, creatinine, albumin, magnesium, calcium, phosphorus, lactate dehydrogenase and sugar according to the methods described earlier [13-15]. Post-operative blood sample analyses were performed 4-6 hrs after surgery and after $24 \mathrm{hrs}$ post-operatively. Normal ranges for biochemical parameters are; lactate 4.5$19.8 \mathrm{mg} / \mathrm{d}$, urea < $50 \mathrm{mg} / \mathrm{dl}$; creatinine $0.5-1.5$ $\mathrm{mg} / \mathrm{dl}$; albumin 3.4-4.8 gm/dl; magnesium 1.70$2.55 \mathrm{mg} / \mathrm{dl}$; calcium $8.6-10.2 \mathrm{mg} / \mathrm{dl}$; phosphorus 2.5-4.5 $\mathrm{mg} / \mathrm{dl}$; sugar $80-160 \mathrm{mg} / \mathrm{dl}$. Data is reported as mean $\pm \mathrm{SD}$.

2.3 Statistical analysis: Biochemical parametric data of Pre, post-operative and during ICUs stay were compared and analyzed by SPSS ver 13.0. Results were considered significant when $\mathrm{P}<0.05$.

\section{Results}

Results are summarized in Table 1 and 2. A total of 75 patients, males $=59$ and females $=16$, were selected for cardiac surgeries with average age of $52.05 \pm 18.65$ years. Six hours postoperative assessment of biochemical parameters inclusive of lactate, showed alerted levels, manifesting postoperative complications and development of comorbid (Table 2). This confirms the correlation of elevated lactic acidosis with slow normalizing of body functions. It was also noted that patients $(\mathrm{n}=$ 21) with higher lactate $>20 \mathrm{mg} / \mathrm{dl}$ (Table 2 ) had to stay longer in ICUs (12-18 days stay, average $16.15 \pm 2.50$ days $)$ as compared to those $(n=54)$ with normal range of lactate level (5-9 days stay, average $7.20 \pm 2.10$ days). Four mortalities were also noted in patients with strong lactic acidosis (>20 mg/dl) as compared to none in group with normal lactate levels. Thirty two patients $(42.66 \%)$, that were underwent cardiac surgeries had previous history of cardiac diseases. Average post-operative (after 6 hours) lactate levels were measured to be $24.55 \pm 18.35 \mathrm{mg} / \mathrm{dl}$ as compared to Pre-operative Lactate levels of $4.15 \pm 1.4 \mathrm{mg} / \mathrm{dl}$.

Table 1: Post-Operative (6 hrs) demographic and lactate levels of cardiac surgery patients

\begin{tabular}{|l|l|}
\hline Parameters & Data, Mean \pm SD \\
\hline Patients & $n=75$ \\
\hline Age & $52.05 \pm 18.65 \mathrm{yrs}$ \\
\hline Gender & -- \\
\hline Males & $59(78.66 \%)$ \\
\hline Females & $16(21.33 \%)$ \\
\hline $\begin{array}{l}\text { History of previous cardiac } \\
\text { diseases }\end{array}$ & $32 / 75(42.66 \%)$ \\
\hline $\begin{array}{l}\text { Lactate levels (Post- } \\
\text { Operative) mg/dl }\end{array}$ & $24.55 \pm 18.35 *$ \\
\hline
\end{tabular}

Results are expressed in mean \pm SD

$*$ Pre-operative Lactate levels $=4.15 \pm 1.4 \mathrm{mg} / \mathrm{dl}$ 


\section{Discussion:}

Earlier studies reported correlation of postoperative mortality with intra and post Hyperlactatemia, mostly in patients that underwent cardiac and critical care surgeries and developed serious co-morbid $[6,12,16]$. Previously reported research studies also suggested that post-operative development of Hyperlactatemia during ICUs stay was a significant indicator of poor outcome in such patients [17-19]. Moreover, onset of Hyperlactatemia as occurred mostly 4-24 hrs postoperatively in some cardiac surgeries results in onset of co-morbid such as hyperglycemia, elevated catecholamine and altered biochemical parameters $[1,8]$ in addition to inducing mortality [20]. Our data also suggested similar correlation as mortality occurred in four patients, all males, which had prolonged ICU stays and lactate greater than $20 \mathrm{mg} / \mathrm{dl}$. Furthermore, those with normalized lactate levels, although did admitted in ICU, recovered early and showed no adverse outcome or mortality.

Table 2: Post-Operative length of stay in hyperlactatemic and normo-lactate cardiac surgery patients

\begin{tabular}{|c|c|c|c|}
\hline Parameters & $\begin{array}{l}\text { Lactate }>20 \\
\mathrm{mg} / \mathrm{dl} \\
\text { (hyperlactatemia } \\
\text { ) } \mathrm{n}=21\end{array}$ & $\begin{array}{l}\text { Lactate 10- } \\
18 \mathrm{mg} / \mathrm{dl} \\
\text { (normo- } \\
\text { lactate) } \mathrm{n}= \\
54\end{array}$ & $\begin{array}{l}\mathrm{P}< \\
0.05\end{array}$ \\
\hline $\begin{array}{l}\text { Length of } \\
\text { stay }\end{array}$ & $\begin{array}{l}16.15 \pm 2.50 \\
(12-18) \text { days }\end{array}$ & $\begin{array}{l}7.20 \pm 2.10 \\
(5-9) \text { days }\end{array}$ & 0.002 \\
\hline $\begin{array}{l}\text { Admission } \\
\text { in ICU }\end{array}$ & $\begin{array}{l}\mathrm{n}=17 \\
(80.95 \%)^{*} \\
{[17 / 21]}\end{array}$ & $\begin{array}{l}\mathrm{n}=10 \\
(18.51 \%) * * \\
{[10 / 54]}\end{array}$ & 0.01 \\
\hline $\begin{array}{l}\text { Duration in } \\
\text { ICU }\end{array}$ & $9.55 \pm 3.65$ days & $\begin{array}{l}4.65 \pm 1.05 \\
\text { days }\end{array}$ & 0.001 \\
\hline $\begin{array}{l}\text { Mortality } \\
\text { (ICU } \\
\text { admitted) }\end{array}$ & $\begin{array}{l}\mathrm{N}=4 \\
(23.52 \%)^{*}\end{array}$ & None & - \\
\hline $\begin{array}{l}\text { Morbidity } \\
\text { (ICU } \\
\text { admitted) } \\
\end{array}$ & $\begin{array}{l}\mathrm{N}=15 \\
(88.23 \%)^{*}\end{array}$ & $\begin{array}{l}\mathrm{n}=6 \\
(60.00 \%)^{* *}\end{array}$ & 0.001 \\
\hline
\end{tabular}

Results are expressed in mean \pm SD

$*$ Percentage w.r.t $\mathrm{n}=17$ patients admitted in ICU

**Percentage w.r.t $\mathrm{n}=10$ patients admitted in ICU

\section{Conclusion:}

Our presented study described the correlation of Hyperlactatemia, 6 hrs post-operatively in cardiac surgery patients with adverse outcomes and lengthy stays in ICUs. In some cardiac surgery patients, that exhibited Hyperlactatemia ( $>20$ $\mathrm{mg} / \mathrm{dl}$ ), ICUs stay extended upto 18 days, with sever co-morbid and four mortalities. Normolactatemia patients stayed less in ICUs, recovered better, and manifested less co-morbidity. It is thus concluded that post-operative Hyperlactatemia and lactic acidosis in cardiac surgery patients is a significant condition to detect poor outcome and post-operative lactate level can predict length of stay in ICUs and any prospect of developing adverse outcome and co-morbid.

\section{References:}

[1]. Jabbari A, Banihashem N, Alijanpour E, Vafaey HR, Aleraza H, Rabiee SM. Serum lactate as a prognostic factor in coronary artery bypass graft operation by on pump method. Caspian J Intern Med 2013; 4 (2): 662-666

[2]. Maillet JM, Le Besnerais P, Cantoni M, Nataf

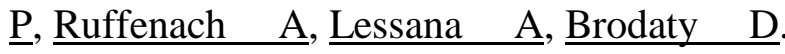
Frequency, risk factors, and outcome of hyperlactatemia after cardiac surgery. Chest 2003; 123: 1361-1366

[3]. Mak NTJJ, Sameena I, de Varennes B, Khwaja K. Outcomes of post-cardiac surgery patients with persistent hyper-lactatemia in the intensive care unit: a matched cohort study. J Cardiothoracic surgery 2016; 11: 33-39

[4]. Boldt J, Piper S, Murray P, Lehmann A. Case 2-1999 severe lactic acidosis after cardiac surgery. Signs of Perfusion defects?. J Cardiothorac Vasc Anesth, 1999; 13 (2): 220224.

[5]. Okorie ON, Dellinger P. Lactate biomarker and potential therapeutic target. Crit Care Clin., 2011; 27 (2): 299-326. 
[6]. Mustafa I. Effects of cardio-pulmonary bypass on lactate metabolism. Intensive Care Med., 2003; 29 (8): 1279-1285.

[7]. Luft FC. Lactic acidosis updates for critical care clinicians. J Am Soc Nephrol., 2001; 12 (1): 1515-1519

[8]. O'Connor E, Fraser JF. The interpretation of peri-operative lactate abnormalities in patients undergoing cardiac surgery. Anaesth Intensive Care. 2012; 40 (4): 598-603.

[9]. Kogan A. The impact of hyperlactatemia on post-operative outcome after adult cardiac surgery. J Anesth 2012; 26 (2): 174-178.

[10]. Zanate B, Kubik M, Reichenspurner H. Lactate level as prognostic factor of mortality in patients after cardiac surgery. Thorac Cardovasc Surg 2010; 58: 43-49

[11]. Mirmohammad-sadeghi M, Etesampour A, Gharipour M, Saeidi M, Kiani A, Shamsolkotabi H, Torknezhad Mr, Farahmand N. Relationship between serum lactate levels and morbidity outcomes in cardiovascular patients after CABG. J Surg Pak Int. 2008; 13 (2): 88-91.

[12]. McNelis J, Marini CP, Jurkiewicz A, Szomstein S, Simms HH, Ritter G, Nathan IM. Prolonged lactate clearance is associated with increased mortality in the surgical intensive care unit. Am J Surg 2001; 182 (5): 481-485.

[13]. Alam JM, Zia ul Islam, Sherwani SK, Asghar SS, Mahmood SR, Sultana I, Ansari MA. Determination of Hyperlactatemia and Acidosis in Adult Patients with Cardiac Diseases and Dysfunctions. FUUAST J. BIOL., 2012; 2(2): 49-54

[14].Alam JM, S.K.Sherwani, Amna Hussain, S.Matinuddin, R.Kausar, Aijaz Ahmed and M.A.Ansari Comparative assessment of analytical performance of conventional chemistry analyzer and modular Cobas 6000 system using routine chemistry parameters. Middle-East Journal of Scientific Research 2014 21(8): 1283-1287.
[15]. Matinuddin S, Alam JM, Amin M, Ali H, Mahmood SK. Precision standardization of lactate assay on Cobas 6000 c501 and comparative analysis with corresponding lactate dehydrogenase concentrations. IJISET-international Journal of innovative Science, Engineering \& Technology: Vol 2 (10): 36-38

[16].Toraman F. Lactic acidosis after cardiac surgery is associated with adverse outcome. Heart Surg Forum 2004; 7 (2): 155-159.

[17].Ranucci M. Anaerobic metabolism during cardio-pulmonary bypass: predictive value of carbon dioxide derived parameters. Ann Thorac Surg., 2006; 811 (6): 2189-2195

[18].Ranucci M. Hyperlactatemia during cardiopulmonary bypass: determinants and impact on post-operative outcomes. Crit Care., 2006; 10: R167.

[19]. Marty P. Lactate clearance for death prediction in severe sepsis or septic shock patients during the first 24 hours in intensive care unit: an observational study. Ann Intensive Care 2013; 3: 3

[20]. Duke T, Butt W, South M, Karl T. Early markers of adverse events in children after cardiac operations. J Thorac Cardiovasc Surg., 1997; 114: 1042-1052

[21]. Hajjar LA, Almeida JP, Fukushima JT, Rhodes A, Vincet JL, Osawa EA, Galas FRBG. High lactate levels are predictors of major complications after cardiac surgery. Surgery 2013; 146 (2): 455-460

[22]. Attana P, Lazzeri C, Picariello C, Dini CS, Gensini GF, Valente S. Lactate and lactate clearance in acute cardiac care patients. Eur Heart J Acute Cardiovasc Care, 2012; 1 (2): 115-121.

[23]. Joudi M, Fathi M, Soltani G, Izanloo A. Factors affecting on serum lactate after cardiac surgery. Anesth Pain Med., 2014; 4 (4): e181514

[24]. Perfacto SM, Casas LSR, Balderas JJ, Azcueta MB. Lactate level as an early 
prognostic marker of major adverse events in Pediatric open heart surgery. Phil Heart Center J 2012; 16 (2): 27-34.

[25]. Meregalli A. Occult hypoperfusion is associated with increased mortality in hemodynamically stable, high-risk, surgical patients. Crit Care 2004; 8 (2): 60-65

[26].Ryan T, Balding J, Mc Govern EM, Hinchion J, Livingstone W, Chughtai Z, Smith OP. Lactic acidosis after cardiac surgery is associated with polymorphism in tumor necrosis factor and interleukin 10 genes. Ann Thorac Surg., 2002; 73: 19051909 